\title{
II. On the microscopic characters of some peculiar forms of coke
}

\section{E. Tulley Newton}

To cite this article: E. Tulley Newton (1876) II. On the microscopic characters of some peculiar forms of coke, Philosophical Magazine Series 5, 1:1, 16-18, DOI: 10.1080/14786447608638996

To link to this article: http://dx.doi.org/10.1080/14786447608638996

曲 Published online: 13 May 2009.

Submit your article to this journal $\pi$

Џll Article views: 2

Q View related articles $\sqsubset$ 
of ourself is dissociated from another part; and the principles which underlie chemical work this hour, become in the next the springs of moral action. Here, then, is neither mist nor vagueness; these tests are decisive and at hand. All real philosophy is human; its foundations lie deep in the granite of every day experience; and the superstructure is lucid as the noon. In that keen light I place the issue.

II. On the Microscopic Characters of some Peculiar Forms of Coke. By E. Tuluey Newton, Assistant Naturalist $H$. $M$. Geological Survey*.

[Plate I.]

TN the extensive collection of fuel substances formed by Dr. Percy, F.R.S., there are certain specimens of Coke presenting. very peculiar forms. The Doctor kindly placed these specimens in my hands that I might have the opportunity of examining them microscopically, and also suggested the desirability of publishing a short account of my observations.

The specimens are of two kinds, both obtained from a cokeoven, and are so unlike each other that there can be no doubt that they have been formed in an entirely different manner. One of them has a silvery metallic lustre, and is usually attached to some object, either as a flat expansion, or in masses of feather-like branches (Plate I. figs. 1 \& 2), having much the appearance of minute stalactites. The surface, which is sometimes smooth, mostly appears to consist of a number of minute globules or bubbles closely packed together. When any considerable thickness is formed it becomes very hard and dense. Specimens of this kind of coke may be seen in the Museum of Practical Geology, Jermyn Street; and perhaps the most remarkable example is that in which some plaited cane and straw, and also some clay tobacco-pipes, are coated over with the most beautiful feathery stalactitic masses of this peculiar coke.

The bubble-like appearance of some specimens might lead one to suppose that they were formed by the bubbling of the semifluid hydrocarbons, in a manner similar to that which may be often seen when ordinary coal is burnt in a grate; but the fact that objects, such as the tobacco-pipes just mentioned, become coated with this coke, shows conclusively that this cannot be the case. And, again, the bubbling process

* Communicated by the Author. 


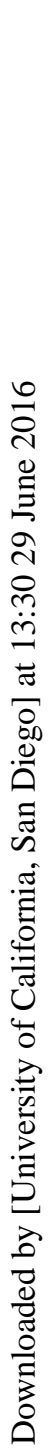
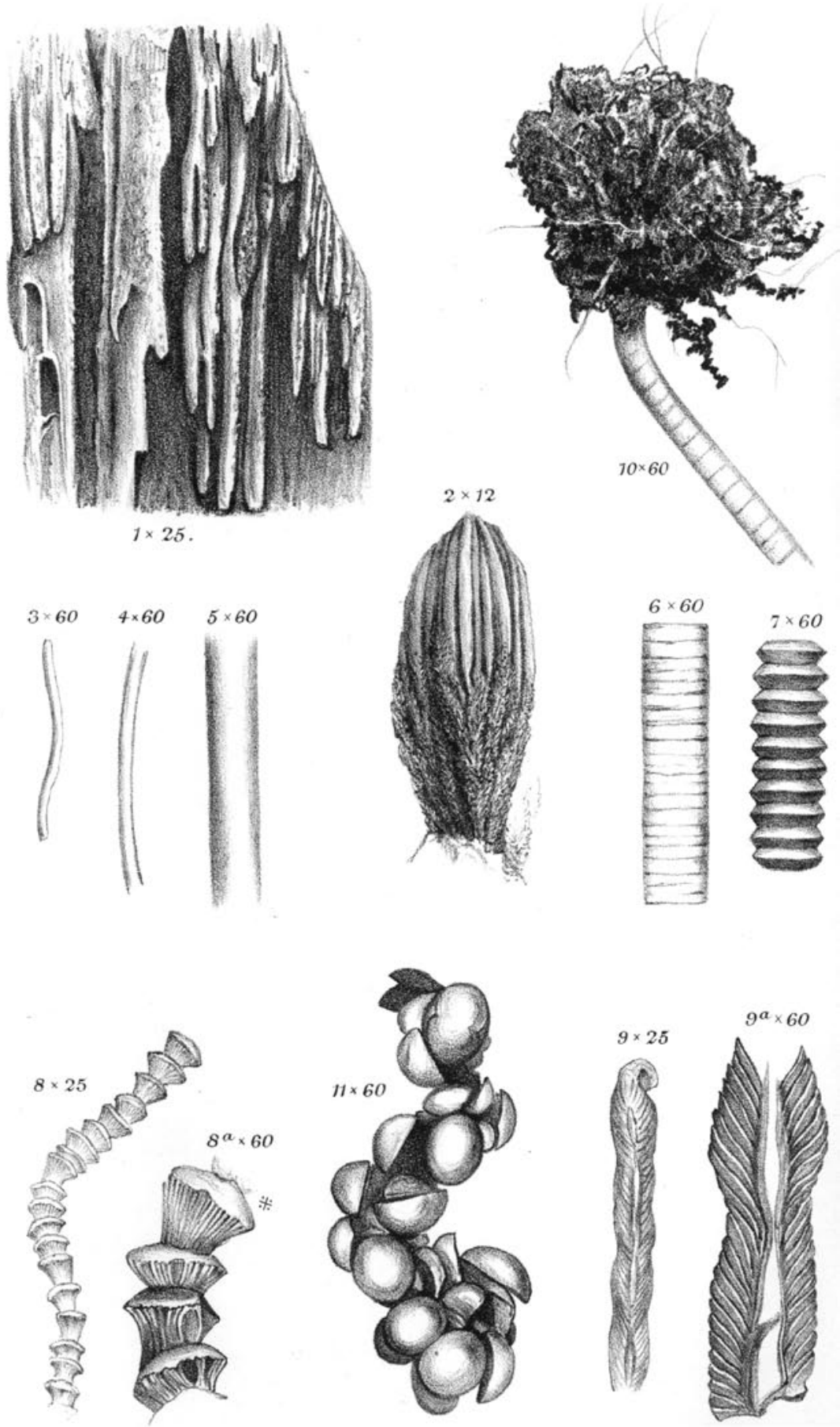

Newton del.G.H.Ford lith.

Mintern Bros .irmp 
produces light vesicular masses, while the kind of which we speak is very dense. It seems most probable that, when the gaseous hydrocarbons evolved in the process of distillation become more highly heated, they are decomposed and a deposition of carbon takes place, as described by Dr. Percy in his volume 'On Fuel,' 1875, p. 419. The Chinese give some of their common earthenware a coating of carbon of this kind, which gives it a metallic lustre. Mr. C. Tookey, formerly of the Japan Mint, tells me that the Japanese use, for the roofs of their houses, tiles which have been coated with carbon in a manner similar to this.

The second kind is that which is commonly known as hairlike coke, and is interesting inasmuch as it presents, when examined with the microscope, a great variety of curious forms. In most instances these "hairs" are of a dull black; but sometimes they have a silvery appearance. The forms assumed are occasionally of such a character that it is difficult to divest one's mind of the idea that they are organic structures.

The "hairs" are not uniform in thickness, but vary from the $\frac{x}{1000}$ of an inch in diameter, or even less, to perhaps the $\frac{1}{100}$ of an inch, or even more. Some are straight or only slightly curved (figs. $3,4,5$ ) ; others are bent, distorted, and knotted in a variety of ways. The finer "hairs" are mostly smooth and cylindrical ; but some have a granular appearance; and occasionally the granules are so large in proportion to the size of the "hair" as to present an irregular knotted appearance, like those forming the tuft of specimens such as fig. 10 . On many of the larger "hairs" more or less distinct transverse markings may be seen (fig. 6) ; and these often become definite constrictions arranged in a very regular manner (fig. 7) so much so that they closely resemble, on a small scale, the moniliform stems of the stone lilies or Encrinites, which are so well known in the Wenlock and Carboniferous Limestones. If one imagines a form such as this drawn out so as to increase the distance between each ridge, the constrictions being at the same time deepened, an appearance such as that given in fig. 8 would be produced. Forms like these are not at all rare. Each segment appears to consist of a bundle of tubes or rods close together where they spring from the segment below, but gradually spreading out as they pass upwards, and terminating abruptly at the rounded surface which forms the top of the segment (fig. $8^{\mathrm{a}}, *$ ). No definite openings could be seen upon the upper rounded surface; but it appeared slightly granular. This form reminds one strongly of certain kinds of tubular Polyzoa, only that it is so much smaller. Fig. 9 represents a form of which there are many varieties, all exhibiting a Phil. Mag. S. 5. Vol. 1. No. 1. .Jan. 1876. 


\section{Mioroscopic Characters of some Peculiar Forms of Coke.}

series of regular ridges passing abliquely outwards from a middle line, which is either a groove, a ridge, or an irregular ridge broken up into segments, as in the figure. This specimen is not cylindrical, but flattened, and has the appearance of being two " hairs" placed side by side and joined to each other at intervals.

Specimens such as that given in fig: 11 do not seem to be so common as some of the others. At first sight this appears like a number of shots irregularly massed together; but upon closer inspection it will be seen that it consists, not of spheres, but of very sharply defined hemispheres, the flat surfaces of which are uniformly turned inwards.

Fig. 10 represents one of a number of forms which resemble minute drumsticks- the knobs of each consisting of a tangled mass of hairs and granules, and giving one the impression that it has been caused by an explosion.

With regard to the internal structure of this hair-like coke, some of the fibres when broken open appear vesicular, while others are solid and have much the aspect of a piece of charcoal. The solid "hairs" must, I think, have been formed in the first place as threads of semifluid carbonaceous material, and subsequently decomposed by being further heated. There is little room for doubting that the vesicular kind of "hairs" have been produced by a process of bubbling, caused by gases forcing their way through the semifluid carbonaceous matters in the manner intimated by Dr. Percy (loc. cit. p. 421). It is not difficult to imagine that such simple forms as those represented in figs. 3, 4, and 5 may have been formed in either of these two ways, or to understand how a series of bubbles formed rapidly one beyond another might produce the moniliform character of fig. 7, although one would scarcely have expected it to be so regular ; but it is not easy to imagine how either process could have produced the regular oblique markings of fig. 9 , or the bundles of tubes (?) seen in the specimen fig. 8 . With regard to the hemispheres (fig. 11), one would like to know how it is that they are so sharply defined as half-spheres, instead of being spheres (or nearly so), as we might have expected them to be-that is, supposing that they are bubbles.

The figures which are given do not represent all the forms which may be seen; they were merely taken as good illustrative examples, the variations and intermediate conditions being well nigh endless.

A specimen of hair-like coke may be seen in the Museum of Practical Geology; but it does not exhibit the various forms alluded to above, in so marked a manner as that in the possession of Dr. Percy. 